\title{
Neferine induces p38 MAPK/JNK1/2 activation to modulate melanoma proliferation, apoptosis, and oxidative stress
}

\author{
Jun Xie $^{1 \#}$, Ming-Hui Chen ${ }^{1 \#}$, Chuan-Peng Ying ${ }^{1}$, Ming-Yi Chen ${ }^{2}$ \\ ${ }^{1}$ Institute of Dermatology and Venereology, Sichuan Academy of Medical Sciences and Sichuan Provincial People's Hospital, Chengdu, China; \\ ${ }^{2}$ Department of Dermatology, Sichuan Academy of Medical Science and Sichuan Provincial People's Hospital, Chinese Academy of Sciences Sichuan \\ Translational Medicine Research Hospital, Chengdu, China \\ Contributions: (I) Conception and design: J Xie, MH Chen; (II) Administrative support: MY Chen; (III) Provision of study materials or patients: CP \\ Ying; (IV) Collection and assembly of data: MY Chen, CP Ying; (V) Data analysis and interpretation: J Xie, MH Chen, CP Ying; (VI) Manuscript \\ writing: All authors; (VII) Final approval of manuscript: All authors. \\ \#These authors contributed equally to this work. \\ Correspondence to: Ming-Yi Chen. Department of Dermatology, Sichuan Academy of Medical Science and Sichuan Provincial People's Hospital, \\ Chinese Academy of Sciences Sichuan Translational Medicine Research Hospital, No. 32 West Second Section, First Ring Road, Chengdu 610072, \\ China. Email: chenmingyi132@sina.cn; Chuan-Peng Ying. Institute of Dermatology and Venereology, Sichuan Academy of Medical Sciences and \\ Sichuan Provincial People's Hospital, No. 32 West Second Section, First Ring Road, Chengdu 610072, China. Email: yingchuanpengsyy1@163.com.
}

Background: Melanoma is a malignant skin cancer that has a poor prognosis in advanced patients. The aim of the present study was to investigate the antitumor role of neferine in melanoma.

Methods: A375 and C32 cells were selected as research vectors in vitro. Cell counting Kit-8, 5-ethynyl-2'deoxyuridine staining, transwell, and flow cytometry assay were used to examined cell malignant phenotypes. Mitochondrial dysfunction was detected by 5,50,6,60-tetrachloro-1,10,3,30-tetraethyl-imidacarbocyanine iodide staining and enzyme-linked immunosorbent assay. Reactive oxygen species (ROS) generation was measured using oxidation sensitive fluorescent probe. The phosphorylation activity of p38 and Jun-Nterminal kinase (JNK) 1/2 were examined by Western blot. A xenograft model was established via the subcutaneous injection of $\mathrm{A} 375$ cells into the right flank of BALB/c mice in vivo.

Results: Neferine $(2.5,5$, or $10 \mu \mathrm{M})$ treatment inhibited proliferation, invasion, and enhanced apoptotic rate of A375 and C32 cells. Neferine treatment induced abnormal changes in mitochondrial membrane potential. Further studies showed that neferine could significantly increase the production of reactive oxygen species (ROS) and 3,4-methylenedioxyamphetamine (MDA) content, decreased the superoxide dismutase (SOD) level. Neferine $(5,10$, or $20 \mathrm{mg} / \mathrm{kg}$ ) obviously suppressed the weight and size of the xenograft tumor, the number of apoptotic cells in vivo, and the expression of $\mathrm{Ki}_{67^{+}}$and survivin ${ }^{+}$decreased. Notably, neferine also activated the phosphorylation of $\mathrm{p} 38$ and JNK1/2.

Conclusions: Neferine inhibits the proliferative and invasion ability of melanoma cells and promotes their apoptosis, ameliorating the malignant progression of melanoma, likely achieved by upregulating the phosphorylation levels of p38 mitogen-activated protein kinase and JNK1/2.

Keywords: Neferine; apoptosis; DNA replication; melanoma; tumorigenesis

Submitted Sep 20, 2020. Accepted for publication Nov 26, 2020.

doi: 10.21037/atm-20-7201

View this article at: http://dx.doi.org/10.21037/atm-20-7201 


\section{Introduction}

Melanoma is a serious form of malignant skin cancer, accounting for $65 \%$ of all skin cancers globally. It is estimated that approximately 55,500 people die of melanoma each year (1). Studies have shown that melanoma originates from melanocytes in the basal layer of the epidermis due to exposure to ultraviolet radiation and malignant transformation of nevi (2). Melanoma is a highly aggressive skin cancer, and its incidence increases each year (3). Traditional surgical and chemoradiotherapy often do not prolong the survival of patients, especially in advanced cases. There is no effective way to treat advanced or metastatic melanoma, although several targeted drugs can prolong the survival of patients with advanced melanoma in clinical treatment (4). Melanoma has a rather poor prognosis, with a 5 -year survival rate of about $10 \%$ in advanced patients (5). Therefore, exploring the molecular mechanisms of melanoma is important clinical diagnosis and treatment.

Mitogen-activated protein kinase (MAPK) plays an important regulatory role in cell growth, differentiation, apoptosis, and stress response (6), which includes extracellular signal-regulated kinase, Jun-N-terminal kinase (JNK), and p38 MAPK. In melanoma, MAPK signaling is involved in the migration and invasion of melanoma cells (7), and JNK supports melanoma cell survival by controlling cell cycle arrest and apoptosis (8). Oxidative stress is involved in the pathological processes of cancer, which has a wide range of significance in apoptosis and non-apoptotic cell death (9), and the reactive oxygen species (ROS) level of cancer cells is higher than that of normal cells (10). Numerous studies have shown that excessive ROS activates p38 MAPK and JNK signals, leading to apoptosis, autophagy, or necrosis $(11,12)$.

Neferine is a dibenzyl isoquinoline alkaloid isolated from the green seed embryo of Nelumbo nucifera Gaertn (13). Studies have shown that neferine possesses high antitumor activity. Liu et al. found that neferine inhibits breast cells growth and metastasis (14). Kalai Selvi et al. reported that neferine promotes the antitumor effect of cisplatin by mediating the mitochondrial apoptosis pathway in lung cancer cells (11). Furthermore, it can induce the cell cycle arrest (G1) of osteosarcoma cells (15). However, the effect of neferine in melanoma has not been elucidated.

In the present study, we investigated the anti-tumor effect of neferine on A375 and C32 cells in vitro. The data indicated that neferine treatment significantly inhibited the cell proliferation, invasion, and promoted apoptosis in melanoma cells. Notably, we demonstrated for the first time that the pro-apoptotic role of neferine in melanoma was mediated by increased ROS production and the activation of p38 MAPK/JNK1/2 pathways. The xenograft tumor model was used to evaluate tumorigenesis in vivo to provide a new medicinal method for melanoma treatment. We present the following article in accordance with the ARRIVE reporting checklist (available at http://dx.doi.org/10.21037/atm-207201).

\section{Methods}

\section{Main materials and reagents}

Neferine (molecular formula: $\mathrm{C}_{38} \mathrm{H}_{44} \mathrm{~N}_{2} \mathrm{O}_{6}$, molecular weight: 624.77, purity: $99.92 \%$ ) was purchased from MedChemExpress (Monmouth Junction, NJ, USA); its chemical structure is shown in Figure 1A. Antibodies from Cell Signaling Technology (Boston, MA, USA) and Abacm (Cambridge, UK) were listed in Table 1. Male BALB/c nude mice (4 weeks old, 16-20 g) were obtained from the Laboratory Animal Center of Sichuan University (Chengdu, China), and were maintained under specific pathogen-free conditions.

\section{Cell culture}

Human malignant melanoma cells A375 and C32 were obtained from China Center for Type Culture Collection (Wuhan, China), and were routinely cultured in Dulbecco's modified Eagle's medium (DMEM; Gibco, Grand Island, NE, USA) at $37^{\circ} \mathrm{C}$ with a $5 \% \mathrm{CO}_{2}$ incubator, supplemented with $10 \%$ fetal bovine serum (FBS; Gibco, USA) and $1 \%$ penicillin/streptomycin (Sigma, St. Louis, MO, USA).

\section{Cell toxicity detection}

A total of $100 \mu \mathrm{L}$ cell suspensions $\left(1 \times 10^{3}\right.$ cells/well $)$ were planted onto 96-well plates (Corning Incorporated, Corning, NY, USA) overnight and then treated with different doses of neferine, from 0.3 to $40 \mu \mathrm{M}$, for $24 \mathrm{~h}$, which was dissolved in $0.1 \%$ dimethylsulfoxide. A total of $10 \mu \mathrm{L}$ Cell Counting Kit-8 (CCK-8) solution was added to each well, according to the manufacturer's instructions, and absorbance at $450 \mathrm{~nm}$ was assessed using a microplate reader (Bio-Rad, Hercules, CA, USA).

\section{5-etbynyl-2'-deoxyuridine (EdU) staining}

Cell proliferation was conducted with the EdU labeling 

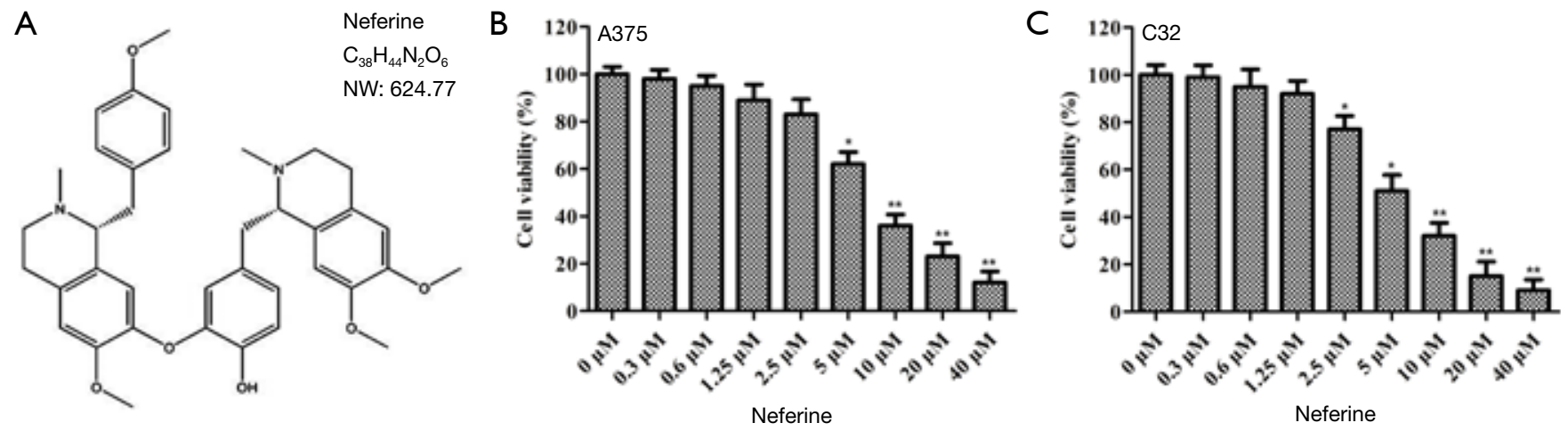

Figure 1 Effect of neferine on melanoma cell cytotoxicity. (A) Chemical structure of neferine; (B,C) cell viability of A375 and C32 cells were detected by cell counting Kit- 8 assay. Data are presented as mean \pm standard deviation. ${ }^{*}, \mathrm{P}<0.05,{ }^{* *}, \mathrm{P}<0.01$ vs. control.

Table 1 Antibody information

\begin{tabular}{|c|c|c|c|c|}
\hline Antibody & Source/isotype & Manufacturer & Art. no. & Molecular weight $(\mathrm{kDa})$ \\
\hline Survivin & Rabbit/lgG & Abcam & $a b 76424$ & 16 \\
\hline MMP2 & Rabbit/lgG & Abcam & ab92536 & 74 \\
\hline MMP9 & Rabbit/lgG & Abcam & $a b 76003$ & 78 \\
\hline $\mathrm{Bcl}-2$ & Rabbit & CST & \#4223 & 26 \\
\hline Cleaved-caspase-3 & Rabbit/lgG & CST & \#9664 & 17 \\
\hline Cleaved-caspase-9 & Rabbit & CST & $\# 9505$ & 35 \\
\hline p38 MAPK & Rabbit & CST & \#9212 & 40 \\
\hline phospho-JNK1/2 & Rabbit/lgG & CST & \#4668 & $46 / 54$ \\
\hline
\end{tabular}

assay using Click-iT EdU Alexa Fluor 647 kit (Invitrogen, Waltham, MA, USA). A375 and C32 cells were seeded onto a 6 -well plate $\left(1 \times 10^{4}\right.$ cells/well $)$ and incubated for $24 \mathrm{~h}$ at $37^{\circ} \mathrm{C}$ with $5 \% \mathrm{CO}_{2}$. A total of $50 \mu \mathrm{M}$ EdU labeling solution was added well for $2 \mathrm{~h}$ under dark conditions, according to the manufacturer's instructions. The cells were fixed with $4 \%$ paraformaldehyde at $37^{\circ} \mathrm{C}$ for $15 \mathrm{~min}$, and stained with Hoechst 33342 (ApexBio, Houston, TX, USA) at $37^{\circ} \mathrm{C}$ for 10 min under dark conditions. Finally, visualized images were captured by an inverted fluorescence microscope (Olympus, Tokyo, Japan). The cell proliferation rate was based on the ratio of EdU-positive nuclei (red)/blue fluorescent nuclei.

\section{Transwell assay}

A375 and C32 cells in serum-free DMEM $\left(4 \times 10^{3}\right.$ cells/ $100 \mu \mathrm{L}$ ) were seeded into the upper chamber of Transwell ${ }^{\circledR}-24$ well permeable supports (Corning, USA) with BD Matrigel (BD, Franklin Lakes, NJ, USA) at room temperature for $30 \mathrm{~min}$. And the lower chamber was filled with $500 \mu \mathrm{L}$ DMEM containing $10 \%$ FBS. After $24 \mathrm{~h}$ of incubation at $37^{\circ} \mathrm{C}$, the membrane and superior lumen cells were wiped off with an aseptic cotton swab. Then, the cells were fixed with paraformaldehyde and stained with crystal violet for $5 \mathrm{~min}$. The invasive cells were visualized (200x magnification) under a light microscope (Nikon, Japan). 
5,50,6,60-tetrachloro-1,10,3,30-tetraethylimidacarbocyanine iodide ( $\mathcal{F C}-1)$ staining

A375 and C32 cells were stained using JC-1, as previously described (16); $1 \times 10^{5}$ cells were resuspended in $200 \mu \mathrm{L}$ DMEM (Gibco, USA) without FBS (Gibco, USA). After $45 \mathrm{~min}$ of incubation, $10 \mathrm{mg} / \mathrm{L} \mathrm{4',6'-diamidino-}$ 2-phenylindole dihydrochloride (Beyotime, Shanghai, China) was added to the suspension to visualize the nuclei. Cell samples were handled using $488 \mathrm{~nm}$ excitation and registration fluorescence (green and red) by NIS-Elements software (Nikon, Tokyo, Japan). The ratio of red and green fluorescence intensities was used as an evaluation of the relative membrane potential.

\section{ROS generation}

2,7-Dichlorodi-hydrofluorescein diacetate (DCFHDA; Sigma, USA) was used to measure intracellular ROS production (17). A375 and C32 cells $\left(1 \times 10^{6}\right.$ cells) were seeded onto a 12-well plate, and then treated with $5 \mathrm{mmol} / \mathrm{L}$ $\mathrm{N}$-acetyl-L-cysteine (Invitrogen, USA) for $1 \mathrm{~h}$. The cells with cultured with neferine $(2.5,5$, or $10 \mu \mathrm{M})$; 6 h later, the medium was replaced with serum-free medium, and $10 \mu \mathrm{M}$ DCFH-DA was added to the incubated cells for 20 min at $37{ }^{\circ} \mathrm{C}$ under dark conditions. Finally, the 2 cells were washed with phosphate-buffered saline (PBS), and dichlorofluorescein fluorescence was immediately assessed by a flow cytometer (Thermo Fisher, Waltham, MA, USA) and analyzed using FlowJo software (BD, Franklin Lakes, NJ, USA).

\section{Cell apoptosis}

Briefly, A375 and C32 cells were washed twice with ice cold PBS, and $1 \times$ binding buffer was used to make a $1 \times 10^{6} \mathrm{cell} / \mathrm{mL}$ suspension. The cells were then mixed with a cell apoptosis analysis kit (Beyotime, Shanghai, China) at room temperature for $15 \mathrm{~min}$ under dark conditions, according to the manufacturer's instructions. Finally, red fluorescence was detected at a $488 \mathrm{~nm}$ wavelength, as well as light scattering using a Attune NxT flow cytometer (Thermo Fisher, USA).

\section{Western blot}

Total protein was treated by RIPA lysis buffer (Beyotime, China), separated by sodium dodecyl sulfate-polyacrylamide gel electrophoresis, and then transferred onto a polyvinylidene difluoride membrane (Bio-Rad, USA). Following post-blocking in Tris-buffered saline with Tween 20 containing $5 \%$ no-fat milk at room temperature for $2 \mathrm{~h}$, the membranes were incubated with primary antibodies against Ki67, survivin, MMP2, MMP9, Bax, Bcl-2, cleavedcaspase-3, cleaved-caspase-9, p38, phospho-p38, JNK1/2, and p-JNK1/2 at $4{ }^{\circ} \mathrm{C}$ overnight, followed by incubation with corresponding antibodies conjugated to horseradish peroxidase for $1 \mathrm{~h}$ at room temperature. Enhanced chemiluminescence reagent was used to expose strips, and quantitative analysis was done using image laboratory software (Bio-Rad, USA); $\beta$-actin was employed as the internal control to standardize sample loading.

\section{Tumorigenesis model}

A xenograft nude model was established in male BALB/c mice; $0.1 \mathrm{~mL}$ cell suspension containing about $5 \times 10^{7} \mathrm{~A} 375$ cells was injected subcutaneously into the right flank region. One week later, tumor size (volume $>200 \mathrm{~mm}^{3}$ ) was used to evaluate whether the tumors successfully formed, and neferine $(5,10$, or $20 \mathrm{mg} / \mathrm{kg})$ or the equivalent volume of ethanol was then injected intraperitoneally every 3 days for 30 consecutive days (18). After 30 days, the mice were killed by cervical dislocation, and tumors were harvested to assess tumor weight or size, followed by terminal deoxynucleotidyl transferase-mediated dUTP nick-end labeling (TUNEL) and immunohistochemical analysis. All experiment procedures were carried out in accordance with the National Institutes of Health (NIH) guide for the Care and Use of Laboratory Animals and were approved by the ethical committees of Sichuan Academy of Medical Sciences.

\section{Histopathological examination}

The steps for the histopathological examination were performed as previously described (19). Tumor tissues were fixed with $10 \%$ formalin and embedded in paraffin. The tissues were cut into $4 \mu \mathrm{m}$-thick slices, and dewaxed and rehydrated in gradient ethanol. Positive apoptotic cells were measured using the One Step TUNEL Apoptosis Assay Kit (Beyotime, China), according to the manufacturer's instructions. The antigen was repaired in $10 \mathrm{mM}$ heated citric acid buffer for $10 \mathrm{~min}$, and the slices were stored in $3 \% \mathrm{H}_{2} \mathrm{O}_{2}$ for $15 \mathrm{~min}$ at room temperature. The slices were incubated with the primary antibodies overnight against Ki67 and survivin at $4{ }^{\circ} \mathrm{C}$. The corresponding secondary 
antibody was incubated at room temperature for $1 \mathrm{~h}$. The $\mathrm{Ki} 7^{+}$and survivin ${ }^{+}$cell images were analyzed with an optical microscope (Olympus, Japan).

\section{Statistical analysis}

All experiments were repeated independently at least 3 times. Data were expressed as the mean \pm standard deviation, and statistical analysis was conducted using SPSS version 25.0 (IBM, Armonk, NY, USA). Two-group or multiple comparisons were done using Student's $t$-test or one-way analysis of variance (ANOVA), followed by Tukey's post-hoc test. $\mathrm{P}<0.05$ indicated a statistically significant difference.

\section{Results}

\section{Screening of the best therapeutic dose of neferine}

Cell cytotoxicity was utilized by CCK-8 assay using A375 and $\mathrm{C} 32$ cells treated with neferine at different doses $(0,0.3,0.6,1.25,2.5,5,10,20$, or $40 \mu \mathrm{M})$ for $24 \mathrm{~h}$. As shown in Figure 1B,C, neferine exhibited an inhibitory effect on A375 and C32 cell viability in a dose-dependent manner; viability decreased slightly without statistical difference with neferine doses $<20 \mu \mathrm{M}$. However, neferine treatment at doses $>20 \mu \mathrm{M}$ exhibited obvious inhibitory effects on the 2 cells. Therefore, neferine doses of 2.5, 5, or $10 \mu \mathrm{M}$ on A375 and $\mathrm{C} 32$ cells were chosen in a subsequent study.

\section{Neferine inbibits the proliferation of human melanoma cells}

As shown in Figure $2 A, B$, the EdU staining showed that the DNA replication rate in $\mathrm{A} 375$ and $\mathrm{C} 32$ cells was significantly downregulated with neferine $(2.5,5$, or $10 \mu M)$ treatment compared with the control group. In addition, CCK-8assay was employed to further verify the inhibition. Compared with the control group, the cell viability was significantly reduced by different doses of neferine treatment (Figure 2C,D). The protein expression levels of Ki67 and survivin were detected by Western blot. As shown in Figure 2E,F,G, neferine significantly decreased the protein levels of Ki67 and survivin compared with the control group.

\section{Neferine attenuates melanoma cell invasion}

In addition to cell proliferation, we also determined the effect of neferine on invasion of A375 and C32 cells. Transwell invasion assay revealed that neferine $(2.5,5$, or $10 \mu \mathrm{M})$ significantly reduced the invasive ability compared with control cells (Figure 3A,B). Matrix metalloproteinases (MMPs) play a key role in tumor invasion by degrading various protein components in extracellular matrix and destroying the tissue barrier of tumor cell invasion (20). Consequently, the cell invasion markers MMP2 and MMP9 were assessed by western blot. Compared with the control group, neferine significantly reduced the expression of MMP2 and MMP9 proteins (Figure 3C).

\section{Neferine promotes mitochondrial dysfunction and apoptosis of human melanoma cells}

As shown in Figure $4 A, B$, the mitochondrial membrane potential of A375 and C32 cells was analyzed using JC-1 staining. We found that the percentage of red/green was reduced following neferine $(2.5,5$, or $10 \mu \mathrm{M})$ treatment. Correlatively, to verify the effect of neferine on apoptosis of A375 and C32 cells, we employed flow cytometry and Western blot. The data showed that the apoptotic rate of A375 and C32 cells markedly increased after neferine treatment $(2.5,5$, or $10 \mu \mathrm{M})$, compared with control group (Figure $4 C, D$ ). Neferine downregulated the protein expression of Bcl-2 and upregulated Bax expression, as well as cleavage of caspase- 3 and caspase- 9 . As a result, the ratio of $\mathrm{Bax} / \mathrm{Bcl}-2$, cleaved caspase-3/caspase-3, and cleaved caspase-9/caspase-9 increased (Figure 4E,F,G).

\section{Neferine induces oxidative stress}

The effect of neferine on oxidative stress was analyzed using DCFH-DA assay. As shown in Figure 5A, A375 and C32 that were treated with neferine $(2.5,5$, or $10 \mu \mathrm{M})$ had significantly higher ROS levels than control cells. Furthermore, compared with the control group, Neferine obviously decreased the superoxide dismutase (SOD) level, and increased 3,4-methylenedioxyamphetamine (MDA) content (Figure 5B,C). To determine whether the apoptosis in melanoma cells is mediated by elevated ROS level, we examined neferine-induced apoptosis in above cells pretreated with $\mathrm{N}$-acetylcysteine (NAC, ROS scavenger). In the presence or absence of NAC $(10 \mathrm{mM}), \mathrm{A} 375$ and C32 cells were pretreated for $1 \mathrm{~h}$, and then were subjected to neferine for $48 \mathrm{~h}$. As expected, NAC caused a significant decrease in ROS levels in A375 and C32 cells treated with neferine (Figure 5D). Importantly, NAC prevented the 


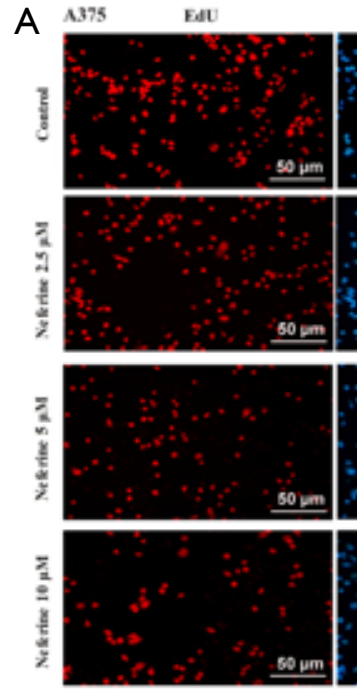

B

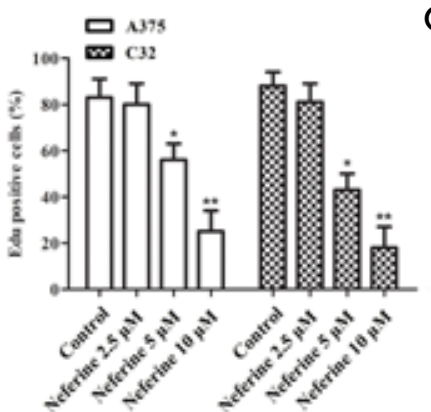

$E$

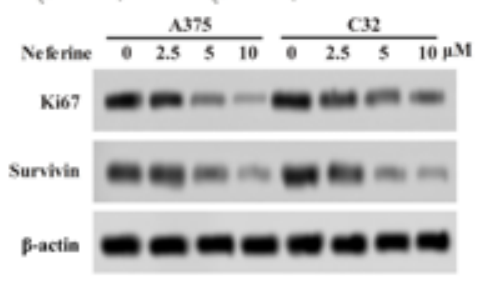

D*P1

C
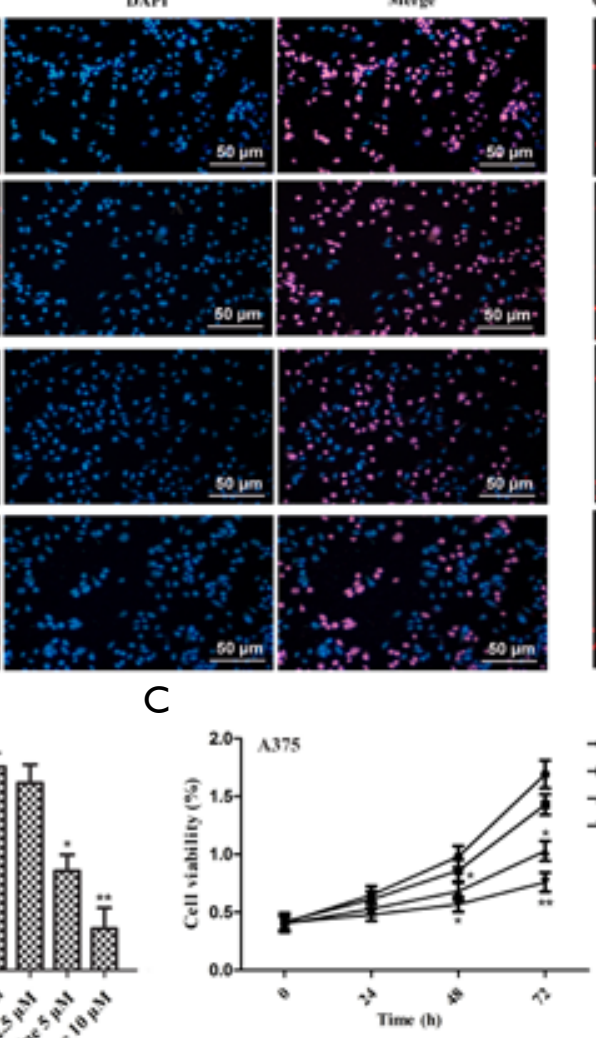

$\mathrm{F}$

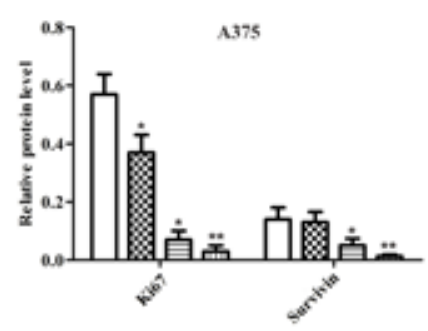

- Control

- Neferine $5 \mu \mathrm{M}$
E.At
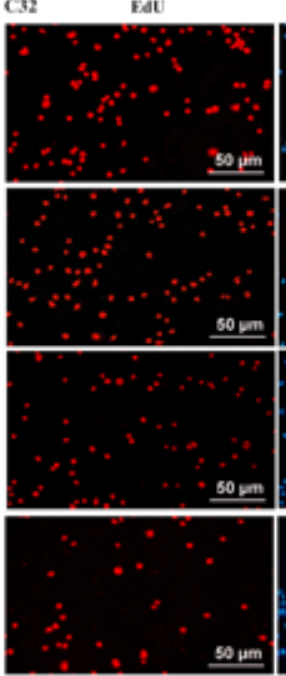

D
DAPI
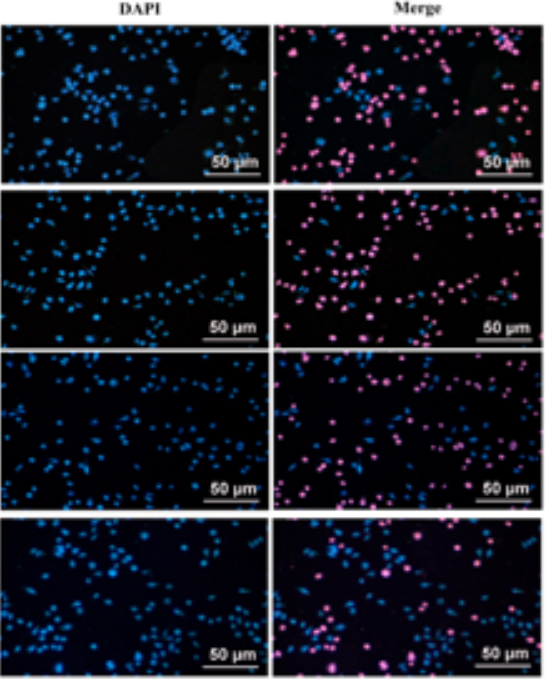

- Neferine $2.5 \mu \mathrm{M}$

$\leftarrow$ Neferine $10 \mu \mathrm{M}$

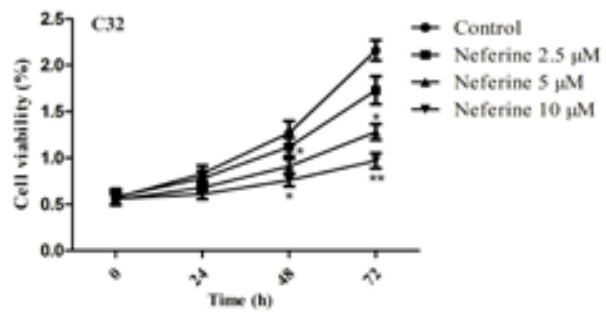

G

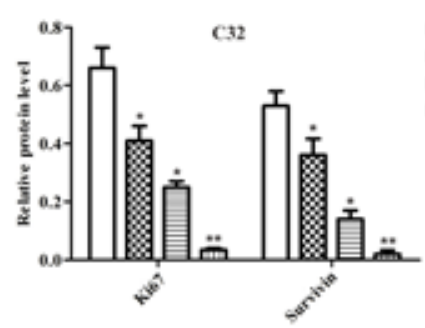
Comirel
Nelerine $2.5 \mu \mathrm{v}$ D Neferine $5 \mathrm{mM}$ 西 Nekerine $10 \mathrm{pM}$

Figure 2 Effect of neferine on melanoma cell proliferation. (A,B) 5-ethynyl-2'-deoxyuridine (EdU) staining of A375 and C32 cells. (C,D) Cell viability of A375 and C32 cells exposed to 0-72 h were detected by cell counting Kit-8 assay. (E,F,G) Relative protein levels of Ki67 and survivin were detected by Western blot in $\mathrm{A} 375$ and $\mathrm{C} 32$ cells. Data are presented as mean \pm standard deviation. ${ }^{*}, \mathrm{P}<0.05,{ }^{* *}, \mathrm{P}<0.01$ vs. control. DAPI, 4',6'-diamidino-2-phenylindole dihydrochloride.

production of ROS and caused a significant reduction in the levels of cleaved caspase-3 and caspase-9 (Figure 5E).

\section{Neferine inhibits melanoma through activation of the $p 38$ MAPK/FNK1/2 patbway}

To elucidate the role of neferine in melanoma, we examined p38 MAPK and JNK1/2 expression. Compared with the control group, the phosphorylation levels of p38 MAPK and JNK1/2 remarkably increased with neferine $(2.5,5$, or $10 \mu \mathrm{M}$ ) treatment (Figure $6 A, B, C$ ). We used $10 \mu \mathrm{M}$ SB203580 to block p38 MAPK activity in A375 cells (Figure 6D) (21). SB203580 significantly increased the level of SOD (Figure $6 E$ ), and reduced MDA content (Figure $6 F$ )

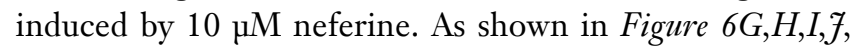
SB203580 increased DNA replication in A375 cells, and reduced the apoptotic rate, but these changes were reversed in A375 cells exposed to $10 \mu \mathrm{M}$ neferine. 
A
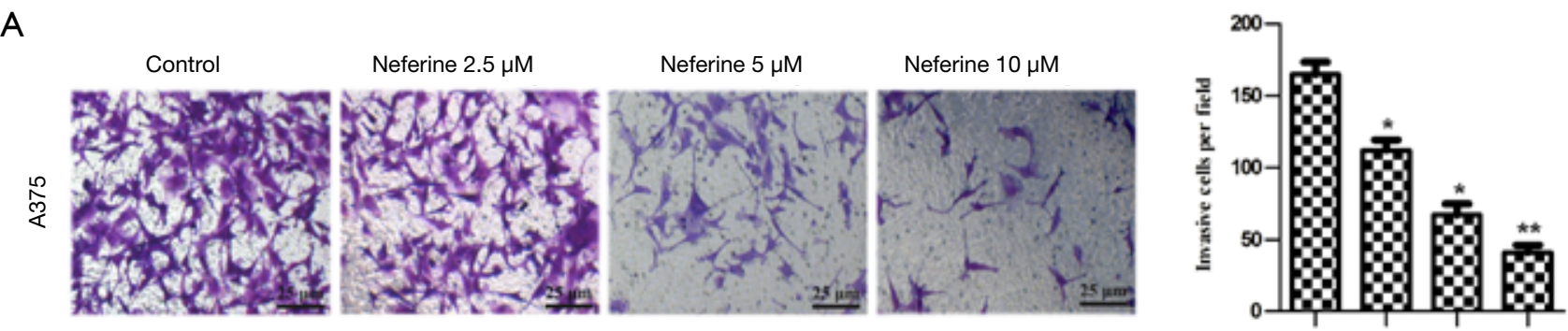

B

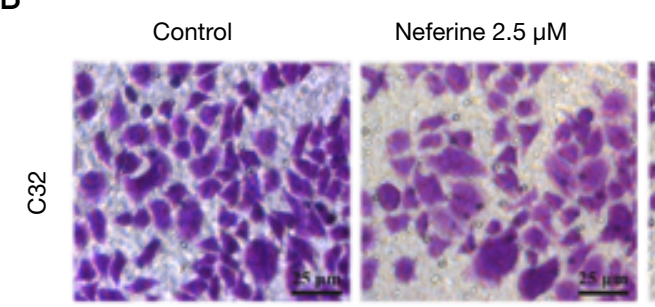

Neferine $5 \mu \mathrm{M}$

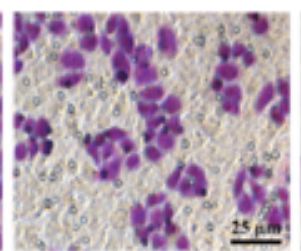

Neferine $10 \mu \mathrm{M}$

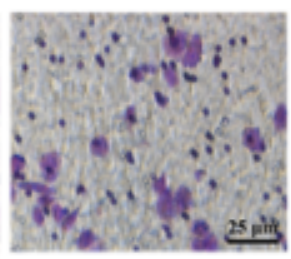

$\square$

C32
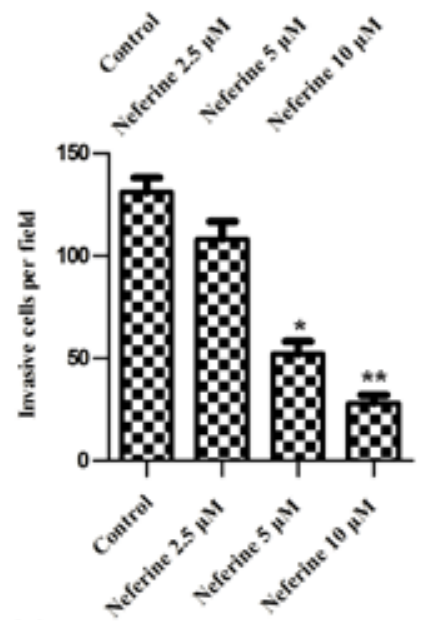

C
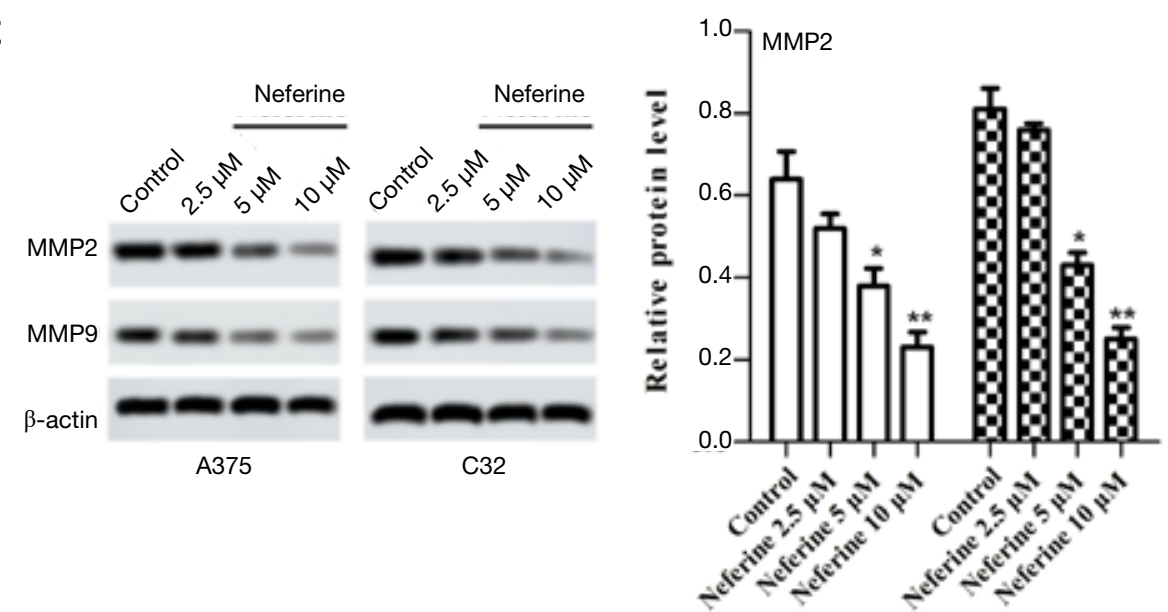

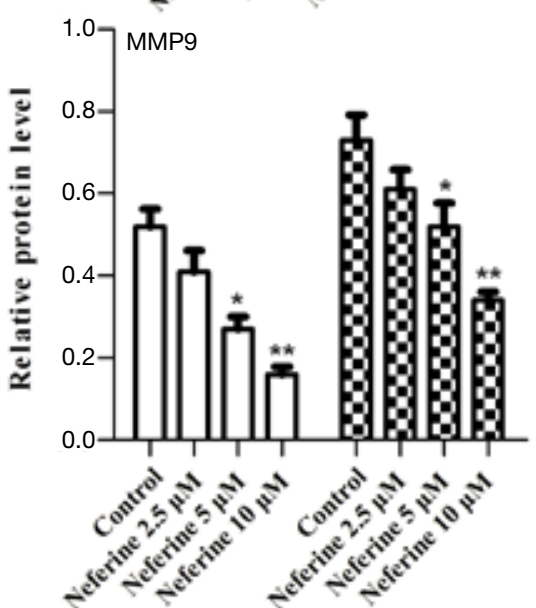

Figure 3 Effect of neferine on melanoma cell invasion. (A,B) The invasion capability of A375 and C32 cells was determined by Transwell assay, magnification at 100x. (C) The protein levels of MMP2 and MMP9 were detected by western blot. Data are presented as mean \pm standard deviation. * $\mathrm{P}<0.05$, **, $\mathrm{P}<0.01$ vs. control.

\section{Neferine inhibits tumorigenesis in vivo}

Xenograft tumors were formed by subcutaneously injecting A375 cells in vivo. The results showed that tumor weight in the neferine $(5,10$, or $20 \mathrm{mg} / \mathrm{kg}$ ) groups and tumor volume were obviously lower compared with the control group, and the inhibition effect of $20 \mathrm{mg} / \mathrm{kg}$ dose was the most obvious. (Figure $7 A, B$ ). The ratio of apoptosis were increased, and the number of Ki $67^{+}$and survivin ${ }^{+}$expression were decreased (Figure 7C,D,E,F). Neferine treatment also obviously suppressed SOD production (Figure $7 G$ ) and increased MDA content (Figure 7H).

\section{Discussion}

Melanoma is a malignant tumor originating from the 

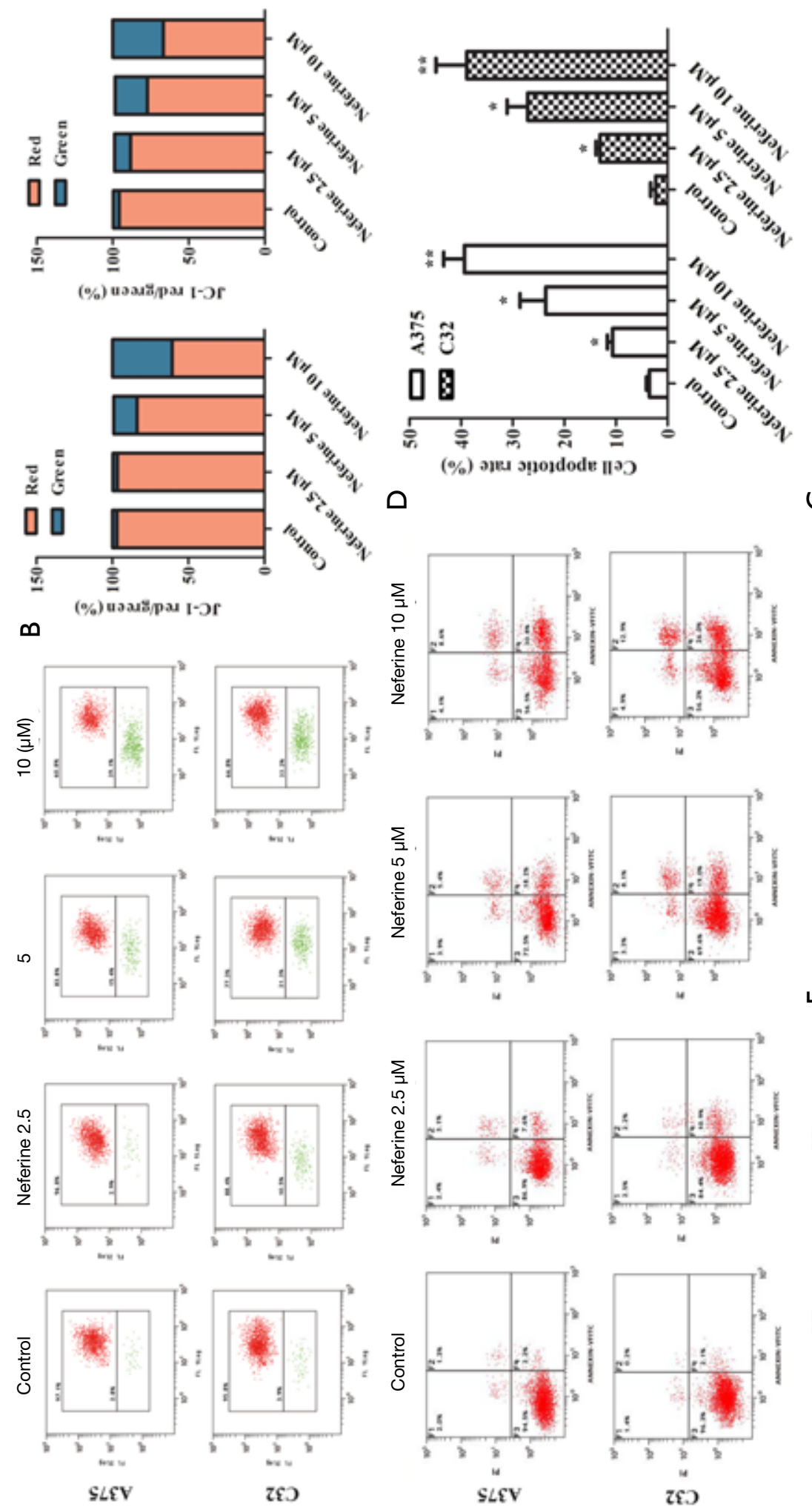

$\varangle^{\text {SLรV }}$ ใรอ $U$
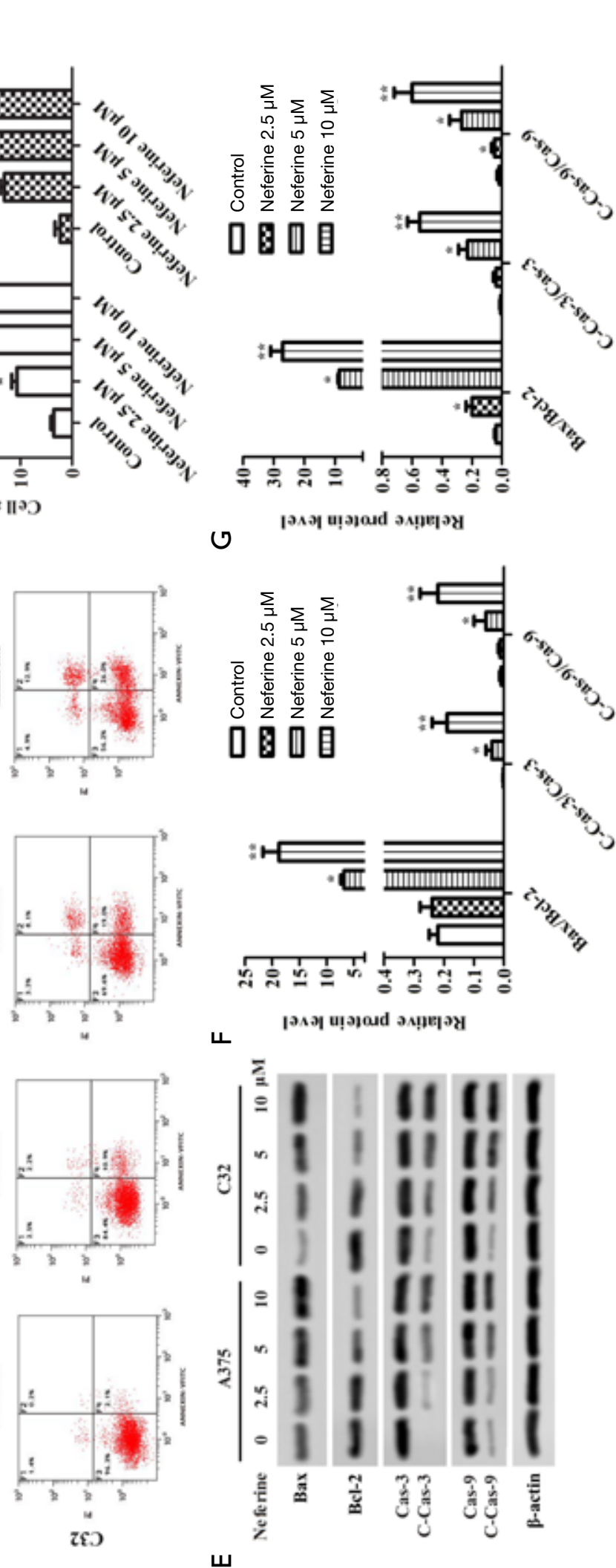

$\checkmark$

ชิ

范芯

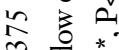

点.

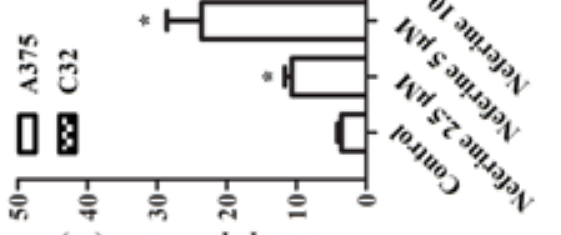

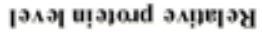

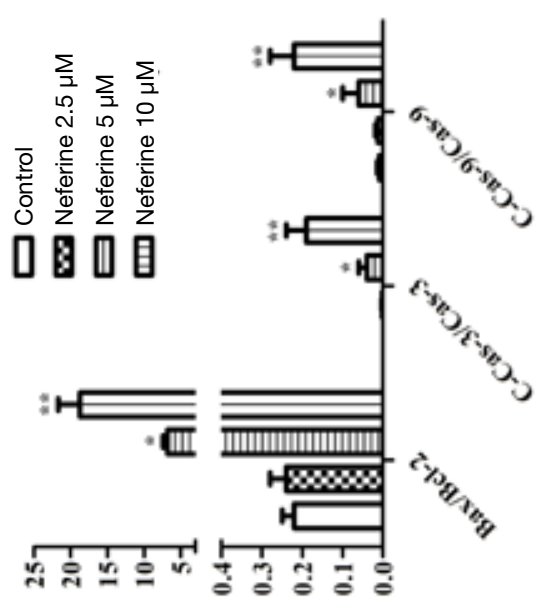

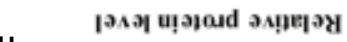

ᄂ

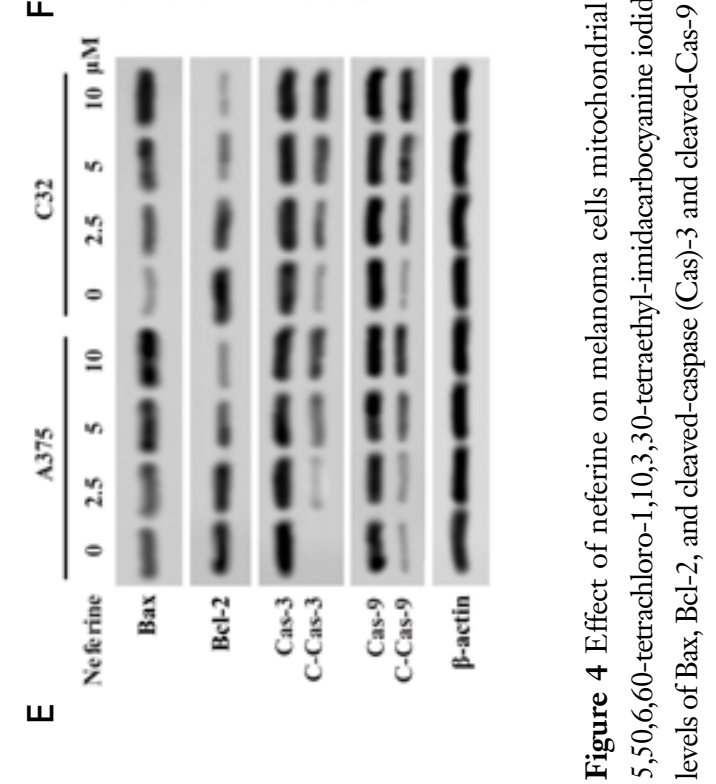

ш 
A

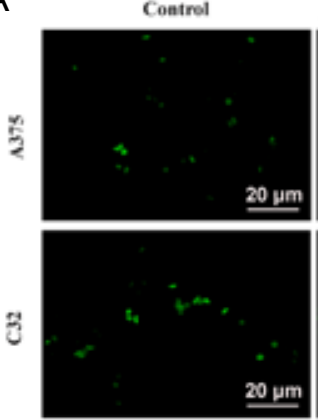

B

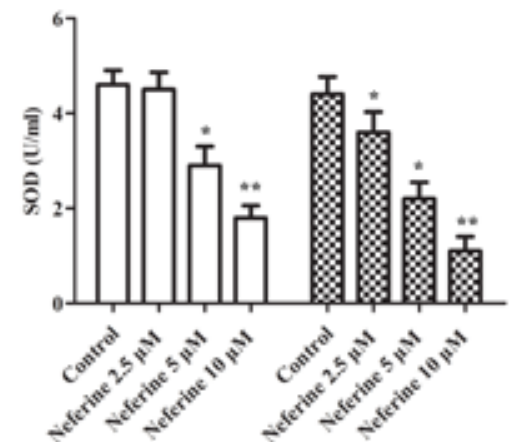

Neferine $5 \mu \mathrm{M}$

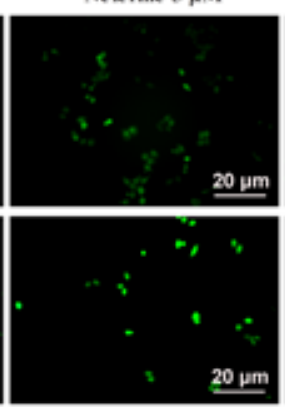

口 ${ }^{A 375}$

C

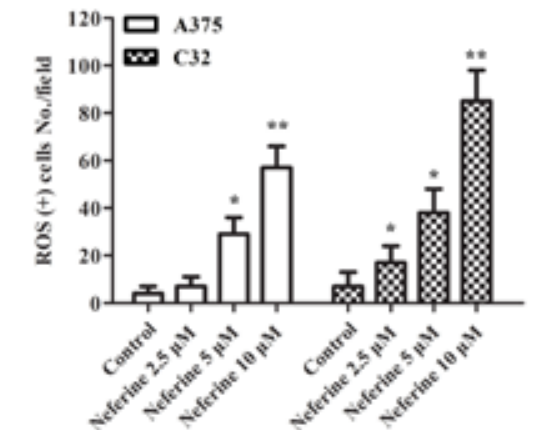

口 $\mathrm{A375}$

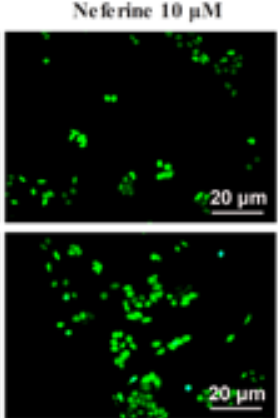

Cor $\mathrm{C}_{2}$
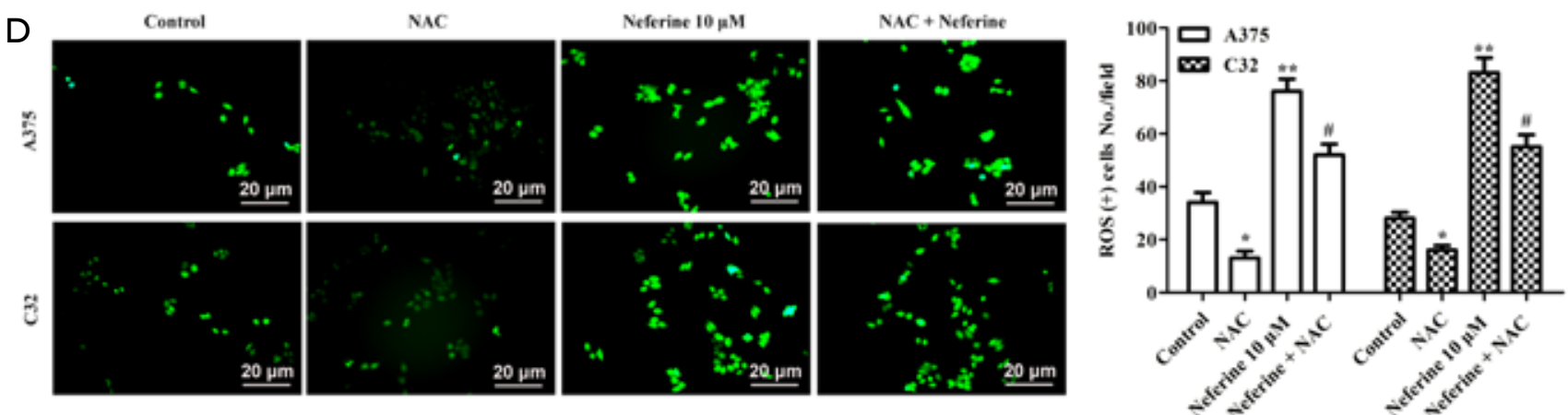

$\mathrm{E}$
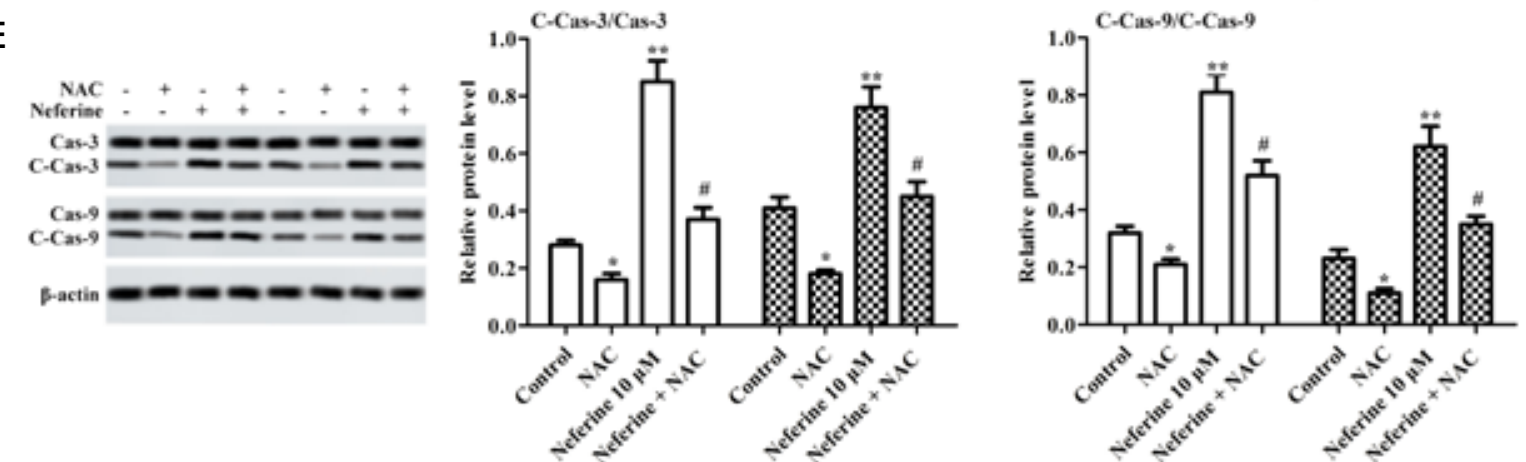

Figure 5 Effect of Neferine on oxidative stress of melanoma cells. (A) Reactive oxygen species (ROS) production was detected by 2,7-dichlorodi-hydrofluorescein diacetate probes. Superoxide dismutase (SOD) level (B) and 3,4-methylenedioxyamphetamine (MDA) content (C) were detected by enzyme-linked immunosorbent assay. (D) Reactive oxygen species (ROS) production was detected by 2,7-dichlorodi-hydrofluorescein diacetate probes. (E) Relative protein levels of cleaved-caspase (Cas)-3 and cleaved-Cas-9 were detected by western blot. Data are presented as mean \pm standard deviation. *, $\mathrm{P}<0.05$, ${ }^{* *}, \mathrm{P}<0.01$ vs. control. ${ }^{*}, \mathrm{P}<0.05$ vs. NAC. NAC, N-acetylcysteine. 

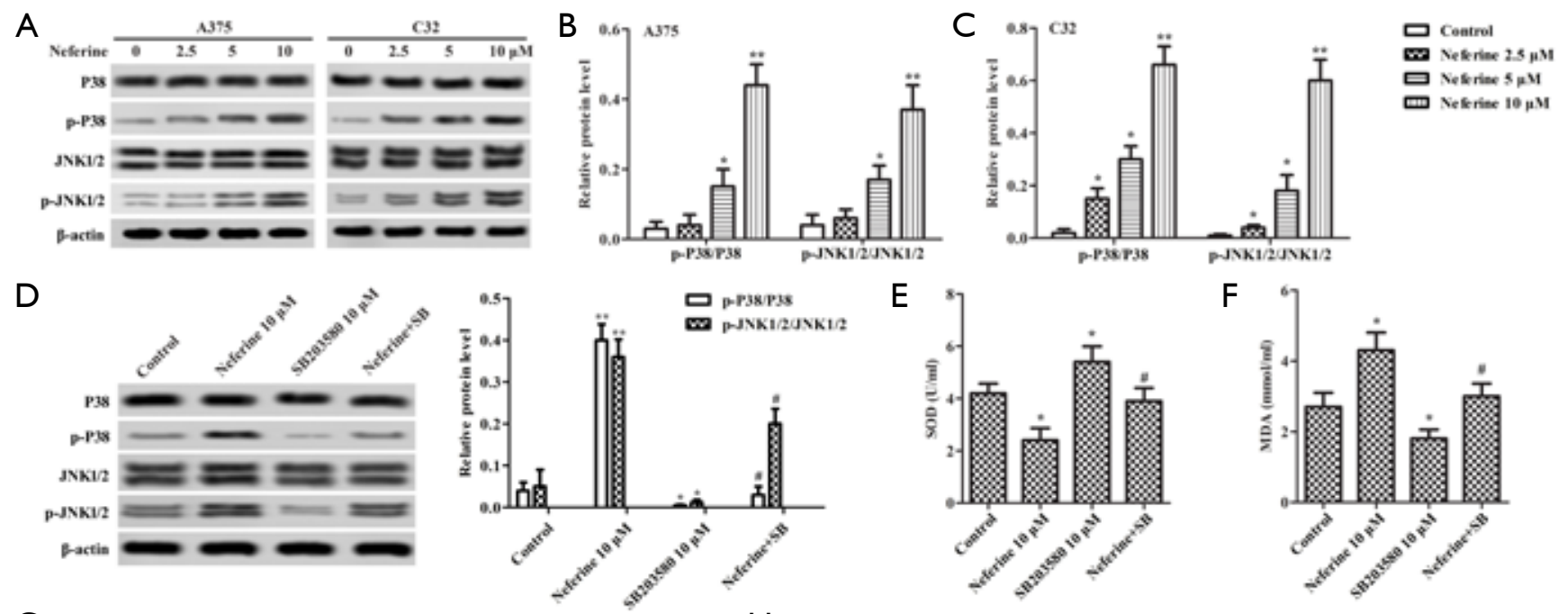

G
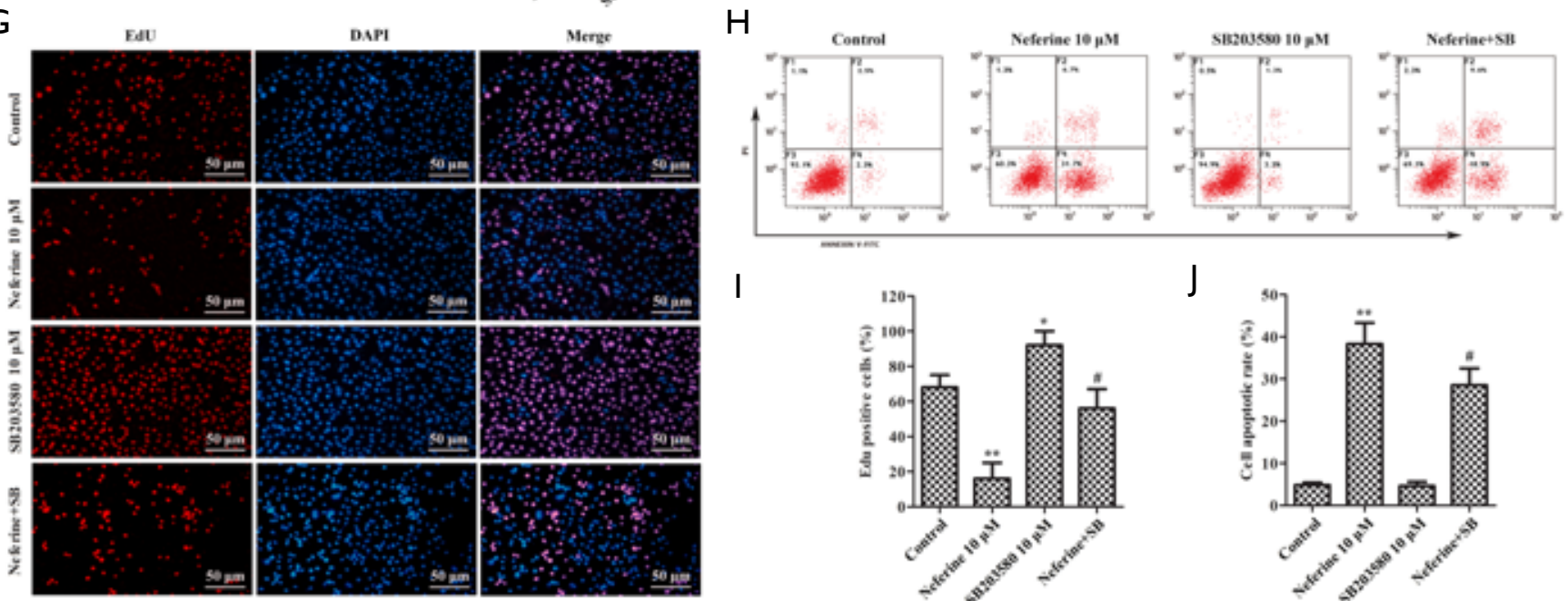

Figure 6 Neferine activates the p38 mitogen-activated protein kinase/Jun-N-terminal kinase (JNK)1/2 pathway. (A,B,C) Expression of p38, p-p38, JNK1/2 and p-JNK1/2 was determined by western blot in A375 and C32 cells. After adding p38 inhibitor SB203580, the expression of p38, p-p38, JNK1/2, and p-JNK1/2 was determined by western blot in A375 cells (D). Superoxide dismutase (SOD) level (E) and 3,4-methylenedioxyamphetamine (MDA) content (F) were detected by enzyme-linked immunosorbent assay in A375 cells. (G,I) 5-Ethynyl2'-deoxyuridine (EdU) staining of A375 cells. $(\mathrm{H}, \mathrm{J})$ Apoptotic ratio of A375 cells. Data are presented as mean \pm standard deviation. * $\mathrm{P}<0.05$, **, $\mathrm{P}<0.01$ vs. control. *, $\mathrm{P}<0.05$ vs. SB203580. DAPI, 4',6'-diamidino-2-phenylindole dihydrochloride.

basal layer of the epidermis; it is a highly aggressive skin cancer with high mortality $(1,2)$. Although drugs and immunotherapy are beneficial to patients with advanced melanoma, there is no effective treatment (5). Therefore, it is important to find a treatment for melanoma. The aim of the present study was to assess the role of neferine in melanoma. We found that neferine contributes to antitumor activity by activating the p38 MAPK/JNK1/2 pathway in melanoma.

Many natural compounds have anti-tumor activity, which confines tumor cell proliferation through multiple mechanisms. Neferine, as a dibenzyl isoquinoline alkaloid, inhibits growth in several cancer cells. Zhang et al. reported that neferine enhances the antitumor effect of imatinib on chronic myeloid leukemia cells in vitro (18). Erdogan et al. confirmed that neferine suppresses the proliferation of $\mathrm{CD} 44^{+}$cancer stem cells through the modulation of apoptosis and cell cycle arrest (22). Liu et al. also found that neferine inhibits MDA-MB-231 cell growth by downregulating the miR-374a/fibroblast growth factor 
A

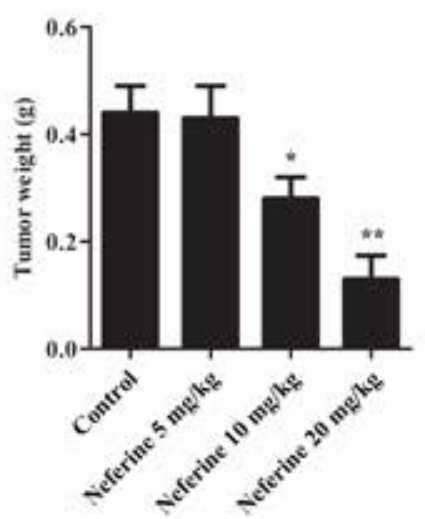

C
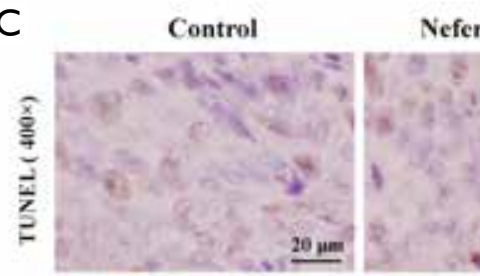

eferine $5 \mathrm{mg} / \mathrm{kg}$
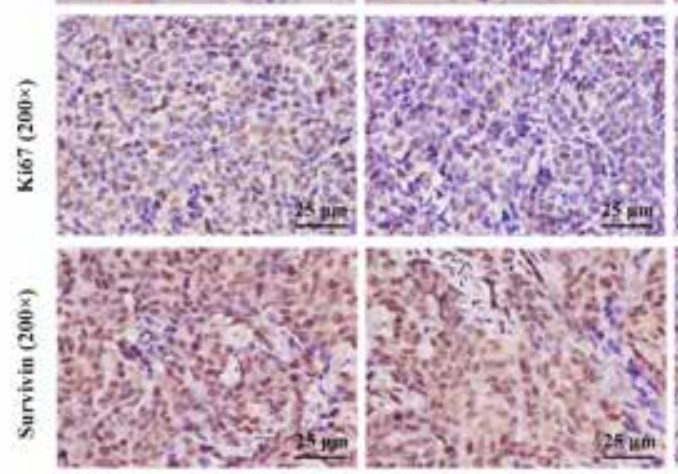

$\mathrm{F}$

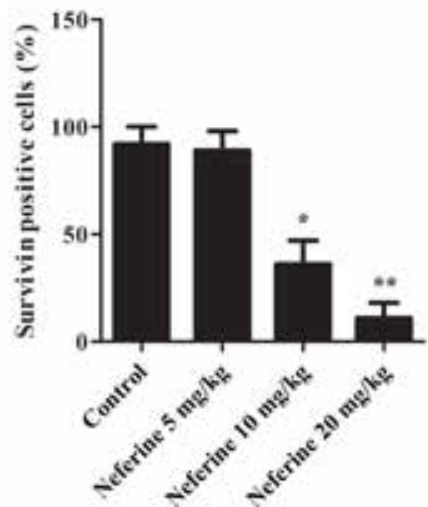

B

G

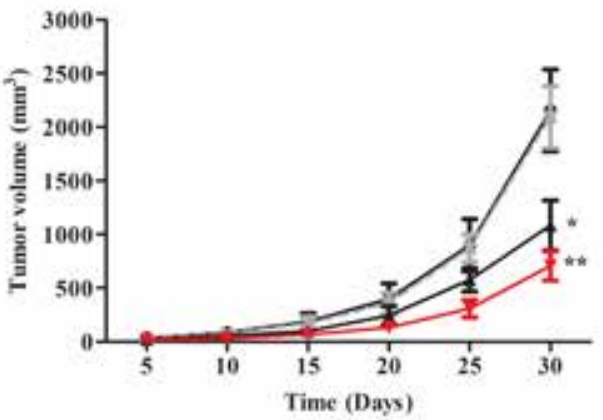

Neferine $10 \mathrm{mg} / \mathrm{kg}$

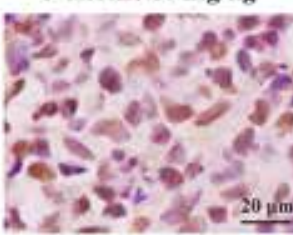

Neferine $20 \mathrm{mg} / \mathrm{kg}$
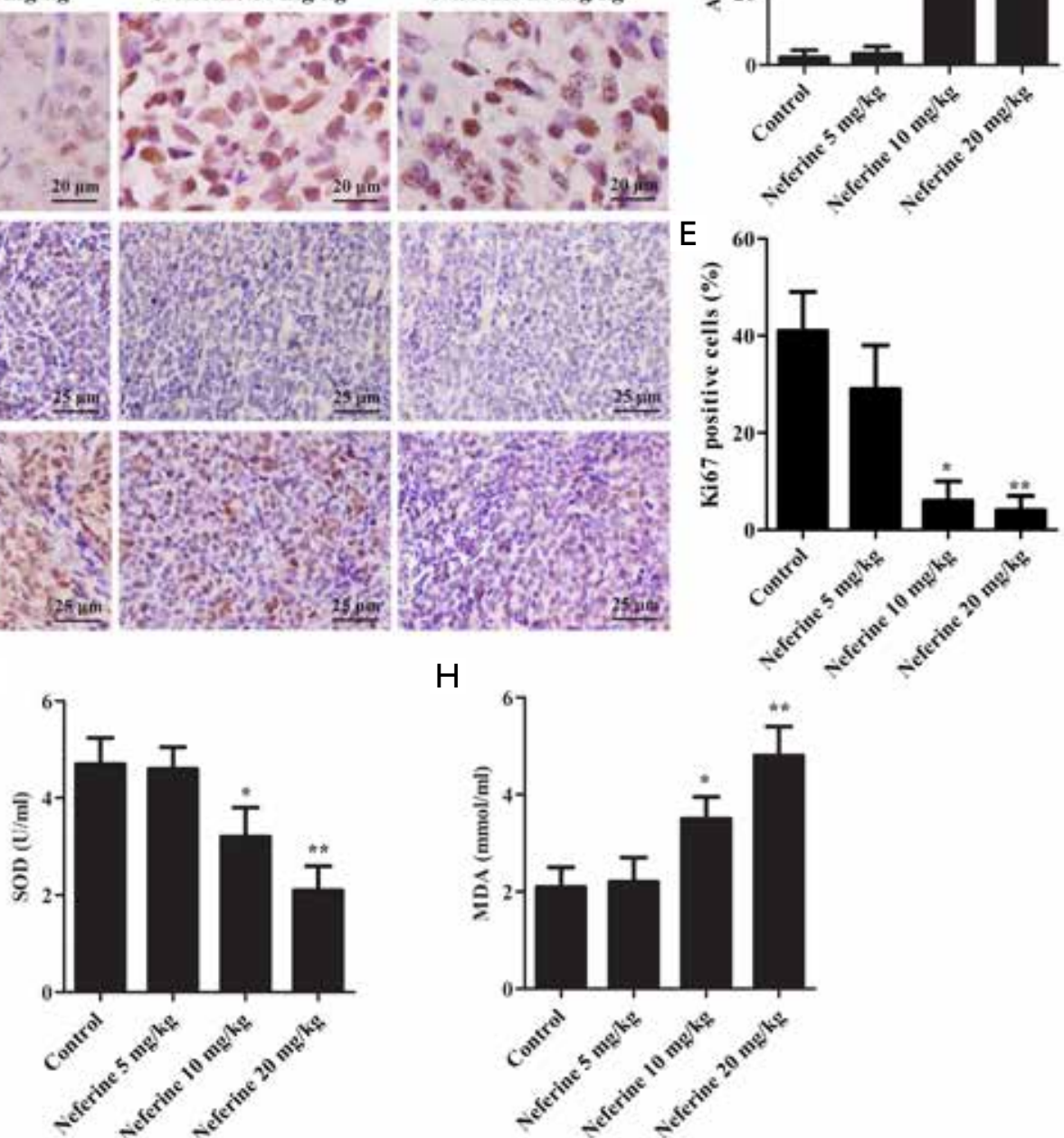

$\mathrm{H}$

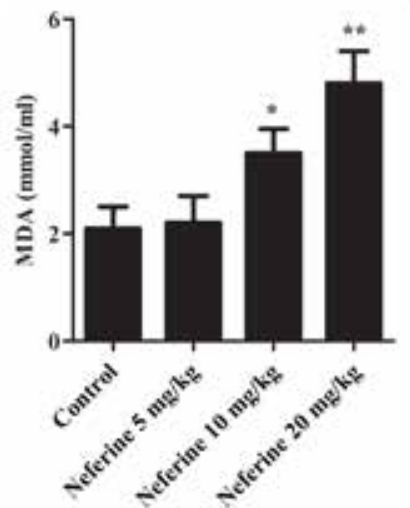

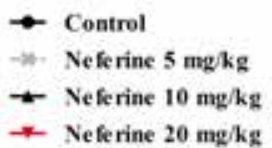

D

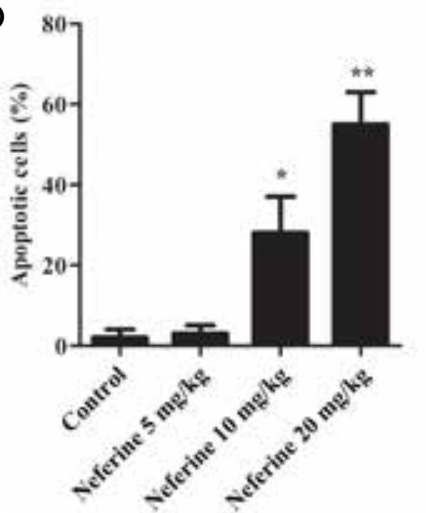

Figure 7 Neferine inhibits tumorigenesis of xenograft tumors in vivo. (A) Tumor weight. (B) Tumor volume. (C,D) Apoptosis ratio was detected by terminal deoxynucleotidyl transferase-mediated dUTP nick-end labeling (TUNEL) staining; representative images were magnified at 400x. (C,E,F) Ki67 ${ }^{+}$and survivin ${ }^{+}$expression detected by immunohistochemical staining; representative images were magnified at 200x. (G,H) Superoxide dismutase level and 3,4-methylenedioxyamphetamine content were detected by enzyme-linked immunosorbent assay. Data are presented as mean \pm standard deviation. ${ }^{*} \mathrm{P}<0.05,{ }^{* *} \mathrm{P}<0.01$ vs. control. 
receptor-2 axis (14). In our study, we found that neferine inhibits cell malignant phenotypes (such as decreased proliferation and invasion, increased apoptotic rate) in vitro and suppresses tumor formation in vivo, indicating that neferine could impede the growth of melanoma. In vitro data indicated that the viability and EdU-positive of A375 and C32 cells were inhibited by neferine at a dose of $2.5,5$, or $10 \mu \mathrm{M}$. In vivo results further found the tumor growth inhibitory role of neferine, manifested by tumor volume and weight, were reduced with 5,10 , or $20 \mathrm{mg} / \mathrm{kg}$ neferine treatment (17).

Apoptosis is a self-destructive process of cell stress, resulting in cell death and reduced cell viability, especially in tumor cells. Some biomarkers are used to monitor the process of apoptosis, including caspases (23), mitochondrial potential (24), and sub G1 group (25). Studies have shown that the main internal and external causes of apoptosis are related to caspases, including caspase-3 and/or caspase-9 (26). Therefore, apoptotic induction is a useful carrier for targeted cancer treatment (27). Previously published literature has demonstrated that neferine causes apoptosis in various cancers, such as lung cancer (13), breast cancer (14), cervical cancer (28), neuroblastoma (29), and glioma (30) by upregulating the expression of caspase- 3 , caspase-9, and $\mathrm{Bax}$, and downregulating the expression of Bcl-2. Therefore, we evaluated the apoptotic effect of neferine on melanoma cells. Our results indicated that neferine obviously induced apoptosis of A375 and C32 cells by increasing cleavedcaspase-3, cleaved-caspase-9, and Bax, and decreasing Bcl-2.

The pharmacological action of neferine is closely related to mitochondrial function, which stimulates mitochondrial-mediated ROS production and leads to caspase-dependent apoptosis (31). Mitochondria are considered to be an important mediator of ROS damage, and elevated ROS levels in oxidized mitochondrial pores can induce apoptosis (32). The most common cause of mitochondrial dysfunction is oxidative stress, and as a result, some researchers have focused on the causes of cancer cell apoptosis in mitochondrial fission (33). In this study, the results demonstrated that neferine elevated the JC-1 red/ green percentage, also reduced the production of SOD and glutathione and increase MDA leakage. Meanwhile, neferine significantly stimulated ROS production in melanoma cells, ROS scavenger NAC could attenuate neferine induced-apoptosis. Our results indicated that neferine treatment triggered mitochondrial dysfunction and promoted oxidative stress in vitro. In an in vivo study, neferine treatment was found to decrease SOD level and the number of positive $\mathrm{Ki} 67^{+}$and survivin ${ }^{+}$cells, and increasing MDA content (18). Therefore, we predict that neferine therapy accelerates cancer tissue apoptosis and inhibits in vivo melanoma tumorigenesis through mitochondrial dysfunction-mediated oxidative stress. Nevertheless, the regulatory role of mitochondrial dysfunction in cancer warrants further investigation.

Interestingly, p38 MAPK and JNK are activated under multiple stress stimuli, and the activated p38 MAPK and JNK play an important role in the antitumor activity of natural products (34). In the present study, we demonstrated that neferine treatment markedly elevates the phosphorylation of $\mathrm{p} 38$ and JNK1/2 activation in both A375 and C32 cells. Neferine can induce apoptosis by activating the p38 and JNK pathways (35), which are activated via ROS generation (36). Furthermore, SB203580, a p38 MAPK inhibitor, reduces the apoptosis of A375 and C32 cells. Others, SB203580 alone also decreased Neferineinduced the levels of MDA and ROS, and increased SOD activity. Together, our work confirmed that Neferine inhibited melanoma through activating p38 MAPK/JNK1/2 pathway.

\section{Conclusions}

The findings of the present study indicate that neferine inhibits proliferation and invasion of melanoma cells. Besides, neferine could promoted apoptosis through mitochondrial dysfunction-mediated ROS generation in vitro. Furthermore, neferine inhibited the weight and volume of tumors in vivo. The antitumor function of neferine in melanoma can be utilized by activation of the p38 MAPK/JNK1/2 pathway. The present study confirms that neferine could be a useful agent against the development of melanoma, and provides a novel approach for melanoma treatment.

\section{Acknowledgments}

Funding: None.

\section{Footnote}

Reporting Checklist: The authors have completed the ARRIVE reporting checklist. Available at http://dx.doi. org/10.21037/atm-20-7201

Data Sharing Statement: Available at http://dx.doi. org/10.21037/atm-20-7201 
Conflicts of Interest: All authors have completed the ICMJE uniform disclosure form (available at http://dx.doi. org/10.21037/atm-20-7201). The authors have no conflicts of interest to declare.

Etbical Statement: The authors are accountable for all aspects of the work in ensuring that questions related to the accuracy or integrity of any part of the work are appropriately investigated and resolved. All experiment procedures were approved by the ethical committees of Sichuan Academy of Medical Sciences and were carried out in accordance with the National Institutes of Health $(\mathrm{NIH})$ guide for the Care and Use of Laboratory Animals.

Open Access Statement: This is an Open Access article distributed in accordance with the Creative Commons Attribution-NonCommercial-NoDerivs 4.0 International License (CC BY-NC-ND 4.0), which permits the noncommercial replication and distribution of the article with the strict proviso that no changes or edits are made and the original work is properly cited (including links to both the formal publication through the relevant DOI and the license). See: https://creativecommons.org/licenses/by-nc-nd/4.0/.

\section{References}

1. Schadendorf D, van Akkooi AC, Berking C, et al. Melanoma. Lancet 2018;392:971-84.

2. Ribero S, Glass D, Bataille V. Genetic epidemiology of melanoma. Eur J Dermatol 2016;26:335-9.

3. Giblin AV, Thomas JM. Incidence, mortality and survival in cutaneous melanoma. J Plast Reconstr Aesthet Surg 2007;60:32-40.

4. Wolchok JD, Kluger H, Callahan MK, et al. Nivolumab plus ipilimumab in advanced melanoma. N Engl J Med 2013;369:122-33.

5. Tang B, Sheng X, Kong Y, et al. Palbociclib for treatment of metastatic melanoma with copy number variations of CDK4 pathway: case report. Chin Clin Oncol 2018;7:62.

6. Plotnikov A, Zehorai E, Procaccia S, et al. The MAPK cascades: signaling components, nuclear roles and mechanisms of nuclear translocation. Biochem Biophys Acta 2011;1813:1619-33.

7. Wang Y, Zhang X, Gao L, et al. Cortistatin exerts antiproliferation and antimigration effects in vascular smooth muscle cells stimulated by Ang II through suppressing ERK1/2, p38 MAPK, JNK and ERK5 signaling pathways. Ann Transl Med 2019;7:561.
8. Alexaki VI, Javelaud D, Mauviel A. JNK supports survival in melanoma cells by controlling cell cycle arrest and apoptosis. Pigment Cell Melanoma Res 2008;21:429-38.

9. Ryter SW, Kim HP, Hoetzel A, et al. Mechanisms of cell death in oxidative stress. Antioxid Redox Signal 2007;9:49-89.

10. He L, He T, Farrar S, et al. Antioxidants maintain cellular redox homeostasis by elimination of reactive oxygen species. Cell Physiol Biochem 2017;44:532-53.

11. Kalai Selvi S, Vinoth A, Varadharajan T, et al. Neferine augments therapeutic efficacy of cisplatin through ROS-mediated non-canonical autophagy in human lung adenocarcinoma (A549 cells). Food Chem Toxicol 2017;103:28-40.

12. Kim JY, Yu SJ, Oh HJ, et al. Panaxydol induces apoptosis through an increased intracellular calcium level, activation of JNK and p38 MAPK and NADPH oxidase-dependent generation of reactive oxygen species. Apoptosis 2011;16:347-58.

13. Sivalingam KS, Paramasivan $P$, Weng CF, et al. Neferine potentiates the antitumor effect of cisplatin in human lung adenocarcinoma cells via a mitochondria-mediated apoptosis pathway. J Cell Biochem 2017;118:2865-76.

14. Liu ZS, Zhang SL, Wang TT, et al. Neferine inhibits MDA-MB-231 cells growth and metastasis by regulating miR-374a/FGFR-2. Chem Biol Interact 2019;309:108716.

15. Zhang $X$, Liu Z, Xu B, et al. Neferine, an alkaloid ingredient in lotus seed embryo, inhibits proliferation of human osteosarcoma cells by promoting $\mathrm{p} 38$ mapk-mediated p21 stabilization. Eur J Pharmacol 2012;677:47-54.

16. Elefantova K, Lakatos B, Kubickova J, et al. Detection of the mitochondrial membrane potential by the cationic dye JC-1 in L1210 cells with massive overexpression of the plasma membrane ABCB1 drug transporter. Int J Mol Sci 2018;19:1985.

17. Lee GH, Jin SW, Kim SJ, et al. Tetrabromobisphenol A induces MMP-9 expression via NADPH oxidase and the activation of ROS, MAPK, and Akt pathways in human breast cancer MCF-7 cells. Toxicol Res 2019;35:93.

18. Zhang Y, Xiao Y, Dong Q, et al. Neferine in the lotus plumule potentiates the antitumor effect of imatinib in primary chronic myeloid leukemia cells in vitro. J Food Sci 2019;84:904-10.

19. Li L, Zhang S, Li H, et al. FGFR3 promotes the growth and malignancy of melanoma by influencing EMT and the phosphorylation of ERK, AKT, and EGFR. BMC Cancer 2019;19:963.

20. Yoon SO, Park SJ, Yun CH, et al. Roles of matrix metalloproteinases in tumor metastasis and angiogenesis. J 
Biochem Mol Biol 2003;36:128-37.

21. Zhang $\mathrm{X}$, Wang $\mathrm{X}, \mathrm{Wu} \mathrm{T}$, et al. Isoliensinine induces apoptosis in triple-negative human breast cancer cells through ROS generation and p38 MAPK/JNK activation. Sci Rep 2015;5:12579.

22. Erdogan S, Turkekul K. Neferine inhibits proliferation and migration of human prostate cancer stem cells through p38 MAPK/JNK activation. J Food Biochem 2020;44:e13253.

23. Fiandalo MV, Kyprianou N. Caspase control: Protagonists of cancer cell apoptosis. Exp Oncol 2012;34:165-75.

24. Shang E, Nguyen TTT, Shu C, et al. Epigenetic Targeting of Mcl-1 Is Synthetically Lethal with Bcl-xL/Bcl-2 Inhibition in Model Systems of Glioblastoma. Cancers (Basel) 2020;12:2137.

25. Wu WC, Liu Y, Liao Y, et al. Fluoropyrimidin-2,4dihydroxy-5-isopropylbenzamides as antitumor agents against CRC and NSCLC cancer cells. Eur J Med Chem 2020;203:112540.

26. Reed JC. Mechanisms of apoptosis. Am J Pathol 2000;157:1415-30.

27. Philchenkov A, Zavelevich M, Kroczak TJ, et al. Caspases and cancer: Mechanisms of inactivation and new treatment modalities. Exp Oncol 2004;26:82-97.

28. Eid W, Abdel-Rehim W. Neferine enhances the antitumor effect of mitomycin-C in Hela cells through the activation of p38-MAPK pathway. J Cell Biochem 2017;118:3472-9.

29. Pham DC, Chang Y, Lin S, et al. FAK and S6K1 inhibitor,

Cite this article as: Xie J, Chen MH, Ying CP, Chen MY. Neferine induces p38 MAPK/JNK1/2 activation to modulate melanoma proliferation, apoptosis, and oxidative stress. Ann Transl Med 2020;8(24):1643. doi: 10.21037/atm-20-7201 neferine, dually induces autophagy and apoptosis in human neuroblastoma cells. Molecules 2018;23:3110.

30. Liang HX, Sun L, Liu N. Neferine inhibits proliferation, migration and invasion of U251 glioma cells by down-regulation of miR-10b. Biomed Pharmacother 2019;109:1032-40.

31. Poornima P, Quency RS, Padma VV. Neferine induces reactive oxygen species mediated intrinsic pathway of apoptosis in HepG2 cells. Food Chem 2013;136:659-67.

32. Moloney JN, Cotter TG. ROS signalling in the biology of cancer. Semin Cell Dev Biol 2018;80:50-64.

33. Rao VA. Targeting mitochondrial fission to trigger cancer cell death. Cancer Res 2019;79:6074-5.

34. Zikaki K, Aggeli IK, Gaitanaki C, Beis I. Curcumin induces the apoptotic intrinsic pathway via upregulation of reactive oxygen species and JNKs in $\mathrm{H} 9 \mathrm{c} 2$ cardiac myoblasts. Apoptosis 2014;19:958-74.

35. Xu L, Zhang X, Li Y, et al. Neferine induces autophagy of human ovarian cancer cells via p38 MAPK/ JNK activation. Tumour Biol 2016,37:8721-9.

36. Hsieh CJ, Kuo PL, Su C, et al. Arctigenin, a dietary phytoestrogen, induces apoptosis of estrogen receptornegative breast cancer cells through the ROS/p38 MAPK pathway and epigenetic regulation. Free Radic Biol Med 2014;67:159-70.

(English Language Editor: R. Scott) 